\title{
Body Composition and Energy Expenditure Changes during Weight Loss: An Exploratory Study
}

\author{
Adrienne S. Thomas ${ }^{1}$, Jocelyn E. Holden ${ }^{2}$, Jo Carol Chezem ${ }^{3}$ \\ ${ }^{1}$ Target Metabolism, Avon, USA; ${ }^{2}$ Department of Educational Psychology, Ball State University, Muncie, USA; ${ }^{3}$ Department of \\ Family and Consumer Sciences, Ball State University, Muncie, USA. \\ Email:00jccchezem@bsu.edu
}

Received October $16^{\text {th }}, 2011$; revised November $26^{\text {th }}, 2011$; accepted December $3^{\text {rd }}, 2011$

\begin{abstract}
The objective of this exploratory study was to describe changes in body composition and resting energy expenditure (REE) in adult women during weight reduction. A total of 69 client records were collected retrospectively from a 25 week commercial weight loss program that restricted calories to $90 \%$ of measured REE. Data analyzed included total body mass (TBM), fat mass (FM) and fat-free mass (FFM) from air displacement plethysmography; measured REE from indirect calorimetry; and predicted REE from linear regression. From baseline to week 25, there were significant declines in TBM $(95.0 \pm 24.1 \mathrm{~kg}$ to $87.2 \pm 22.9 \mathrm{~kg} ; P<0.001)$ and FM $(47.5 \pm 18.5 \mathrm{~kg}$ to $39.9 \pm 17.6 \mathrm{~kg} ; P<0.001)$. During the same time period, FFM remained unchanged (47.5 $\pm 7.3 \mathrm{~kg}$ to $47.2 \pm 7.0 \mathrm{~kg} ; P \geq 0.05$ ). REE was signifycantly lower at weeks $13(6595.2 \pm 1312.1 \mathrm{~kJ})$ and $25(6608.2 \pm 1404.6 \mathrm{~kJ})$ compared to baseline $(7117.4 \pm 1471.5 \mathrm{~kJ})$ $(P<0.001)$; however, REE at weeks 13 and 25 were similar $(P \geq 0.05)$. At weeks 13 and 25, predicted REE $(6992.7 \pm$ 1065.7 and $6939.2 \pm 1056.0 \mathrm{~kJ}$, respectively) was significantly higher than measured REE $(6595.2 \pm 1312.1$ and 6608.2 $\pm 1404.6 \mathrm{~kJ}$, respectively) $(P<0.001)$. The results of this study suggest that significant reduction in TBM is possible without the loss of FFM and that metabolic adaptation may occur during the process.
\end{abstract}

Keywords: Energy Metabolism; Body Composition; Caloric Restriction; Weight Loss

\section{Introduction}

Obesity continues to be a major health threat in the United States. Results from the National Health and Nutrition Examination Survey (NHANES) 2007-2008 indicate $68 \%$ of adults are overweight or obese [1]. Not surpriseingly, the majority of Americans are concerned about their weight, with $54 \%$ actively engaged in weight reduction [2].

Overweight and obese individuals use a variety of strategies for weight loss. Those most commonly identified include reducing caloric intake, altering the types of food eaten and participating in physical activity [2]. Previous research indicates that these methods can be effective in reducing total body mass (TBM) $[3,4]$. While much of TBM loss is from fat mass (FM), there is a significant reduction in fat-free mass (FFM) as well $[5,6]$. Furthermore, resting energy expenditure (REE) may be lowered as a consequence of caloric restriction and body composition changes [7-9].

Target Metabolism is a commercial weight loss company operating in the Midwestern United States. The goal of its structured 25-week program is to reduce TBM, through FM loss, with a combination of individualized
REE-based caloric restriction (target of $90 \%$ REE) and cognitive behavior therapy. Target Metabolism obtains serial measurements of body composition by air displacement plethysmography and REE by indirect calorimetry from all clients. These technology-based assessments provide a unique opportunity to investigate changes during the weight loss process. The purpose of the current study was to conduct an exploratory analysis of changes in body composition and REE in adult women during weight reduction.

\section{Experimental Methods}

\subsection{Samples}

The study utilized previously collected data from the commercial weight loss program. Data from 69 female clients, aged $18-70$, who had completed the 25 -week program were included in the analysis.

\subsection{Data Collected}

All information was obtained retrospectively from client records in a de-identified form following approval from the sponsoring agency's Institutional Review Board. At 
entry into the program (baseline), TBM and body composition (including FFM, FM and percent body fat) were assessed using air displacement plethysmography (Bod Pod S/T, Life Measurement, Inc., Concord, CA), and REE was determined by indirect calorimetry (ReeVue indirect calorimeter, Korr Medical Technologies, Salt Lake City, UT) using the method of Weir [10]. During the program, TBM and body composition were measured at two-week intervals. At weeks 13 and 25, REE was reassessed with adjustments of daily caloric intake to maintain $90 \%$ REE. Clients' age and height were obtained from a medical history questionnaire.

\subsection{Statistical Procedures}

Data were analyzed using SPSS, version 17.0 (SPSS Inc., Chicago, IL). The level of significance was set at $P \leq$ 0.05 . One participant was missing REE at week 25; to coplete the data set, her REE from week 13 was carried forward to week 25. Repeated measures analysis of variance (ANOVA) was used to compare absolute values and changes in TBM, FFM, FM, percent body fat, and REE at baseline, week 13 and week 25. Mauchly's test of sphericity was utilized to assess assumptions of repeated measures ANOVA. Linear regression analysis was employed to develop a predictive equation for REE based on measurements of FFM, FM and age at baseline. Using this equation, predicted REEs were calculated from measurements of FFM and FM at weeks 13 and 25. Paired ttest was then used to compare predicted and measured REE at these two time points.

\section{Results}

Data from 69 females were included in the analysis. On average, subjects were $44.5 \pm 11.1$ years old and $165.1 \pm$ $6.1 \mathrm{~cm}$ at program entry. Table 1 provides additional information on body composition and REE of subjects at baseline and at weeks 13 and 25 .

TBM was significantly lower at weeks $13(89.7 \pm 23.2$ $\mathrm{kg}, 5.6 \%)$ and $25(87.2 \pm 22.9 \mathrm{~kg}, 8.4 \%)$ compared to baseline $(95.0 \pm 24.1 \mathrm{~kg})(P<0.001)$. Average TBM was also significantly lower at week 25 compared to week 13 $(2.8 \% ; P<0.001)$.

There was no significant difference in FFM at baseline $(47.5 \pm 7.3 \mathrm{~kg})$ and weeks $13(47.3 \pm 7.1 \mathrm{~kg}, 0.4 \%)$ and $25(47.2 \pm 7.0 \mathrm{~kg}, 0.6 \%)(P>0.05)$. In contrast, FM at weeks $13(42.5 \pm 17.9 \mathrm{~kg}, 10.5 \%)$ and $25(39.9 \pm 17.6 \mathrm{~kg}$, $16.6 \%)$ was significantly lower than baseline $(47.5 \pm$ $18.5 \mathrm{~kg})(P<0.001)$. FM at week 25 was also significantly lower than week $13(6.1 \%, P<0.001)$. These changes to FM led to significant reductions in body fat percentage at weeks $13(47.4 \% \pm 7.7 \%)$ and $25(45.8 \% \pm$ $7.7 \%)$ compared to baseline $(50.0 \% \pm 7.8 \%)$. Percent body fat was also significantly lower at week 25 compared to week $13(1.6 \%, P<0.001)$.

Measured REE was significantly lower at weeks 13 $(6595.2 \pm 1312.1 \mathrm{~kJ}, 7.3 \%)$ and $25(6608.2 \pm 1404.6 \mathrm{~kJ}$, $7.3 \%)$ compared to baseline $(95.0 \pm 24.1 \mathrm{~kg})(P<0.001)$. Measured REE at weeks 13 and 25 was not significantly different $(P \geq 0.05)$. At baseline, subjects' measured REE was significantly correlated with age $(\mathrm{r}=-0.255, \mathrm{n}=69$, $P=0.017)$, FFM $(\mathrm{r}=0.728, \mathrm{n}=69, P<0.001)$ and FM $(\mathrm{r}=0.612, \mathrm{n}=69, P<0.001)$. An equation was developed to predict REE in subjects at weeks 13 and 25 . REE $=422.8+24.4($ FFM in $\mathrm{kg})+4.8(\mathrm{FM}$ in $\mathrm{kg})-3.2(\mathrm{age}$ in years). Using this equation, predicted REE was significantly greater than measured REE at weeks 13 (6992.7 \pm $1065.7 \mathrm{~kJ}$ versus $6595.2 \pm 1312.1 \mathrm{~kJ})$ and $25(6339.2 \pm$ $1056.0 \mathrm{~kJ}$ versus $6608.2 \pm 1404.6 \mathrm{~kJ})(P<0.001)$.

\section{Discussion and Conclusions}

\subsection{Discussion}

Subjects consuming a calorie-restricted diet, targeted at $90 \%$ of REE, had a significant decline in TBM during the 25 -week program. These results are comparable to those obtained in previous studies of similar durations and populations. In a study by Kerksick et al. [11] that explored the effects of resistance-based exercise and macronutrient composition in pre-menopausal obese women, subjects who consumed a calorie-restricted diet containing 5021 $\mathrm{kJ}$ with exercise, lost an average of $4 \mathrm{~kg}$ over 14 weeks.

Table 1. Body composition and resting energy expenditure.

\begin{tabular}{cccc}
\hline & Baseline & Week 13 & Week 25 \\
\hline Total body mass (kilograms) & $95.0 \pm 24.1^{\mathrm{a}}$ & $89.7 \pm 23.2^{\mathrm{b}}$ & $87.2 \pm 22.9^{\mathrm{c}}$ \\
Fat-free mass (kilograms) & $47.5 \pm 7.3^{\mathrm{a}}$ & $47.3 \pm 7.1^{\mathrm{b}}$ & $47.2^{\mathrm{b}} \pm 7.0^{\mathrm{a}}$ \\
Fat mass (kilograms) & $47.5 \pm 18.5^{\mathrm{a}}$ & $42.5 \pm 17.9^{\mathrm{b}}$ & $39.9 \pm 17.6^{\mathrm{c}}$ \\
Body fat (percent) & $50.0 \pm 7.8^{\mathrm{a}}$ & $47.4 \pm 7.7^{\mathrm{b}}$ & $45.8 \pm 7.7^{\mathrm{c}}$ \\
Resting energy expenditure (kilojoules) & $7117.4 \pm 1471.5^{\mathrm{a}}$ & $6595.2 \pm 1312.1^{\mathrm{b}}$ & $6608.2 \pm 1404.6^{\mathrm{a}}$ \\
\hline
\end{tabular}

Values shown are means $\pm \mathrm{SD}$. For each variable, values not sharing the same letters were significantly different. $P<0.001$. 
Redman et al. [12], comparing the effects of a $25 \%$ energy deficit from diet or from a combination of diet and aerobic exercise in overweight adults, observed an $8 \mathrm{~kg}$ reduction in TBM in both groups over six months. Franz et al. [3], in a systematic review of randomized weight loss trials in adults with at least one year of following up, reported a mean weight loss of $5-8.5 \mathrm{~kg}$ in the first six months among studies employing calorie-restricted diets and/or weight loss drugs. Together, these studies illustrate that caloric restriction, whether applied uniformly or calculated individually, can be an effective strategy for TBM reduction. Adaptation of energy expenditure during weight reduction is common; however, the decline of REE in the current study (13.5 kcal/kg TBM loss) was less than observed in previous studies of calorie-restricted diets (19.31 - $52.6 \mathrm{kcal} / \mathrm{kg}$ TBM loss) [13]. The observed discrepancy between measured and predicted REE lends support to reports of metabolic adaptation by Redman et al. [9] and Tremblay \& Chaput [14] and highlight the benefit of measuring rather than estimating energy expenditure during weight loss. In the current study, adjustment of target caloric intake to reflect changes in body composition and metabolic adaptation during the program may have prevented plateaus of TBM and FM often observed with caloric restriction $[8,14]$.

In the current study, reduction in TBM was due to loss in FM, with no significant decline in FFM. These findings are in contrast with previous weight loss studies. Kersick [11] noted a significant decline in FFM over a 14week period using a calorie-restricted diet with varying macronutrient composition and resistance-based exercise. Redman [12] also observed significant loss of FFM with a calorie-restricted diet in the presence or absence of aerobic exercise. The reason for FFM maintenance in the current study may be related to the program's caloric target of $90 \%$ REE. In a systematic review of changes in REE during weight loss, Schwartz and Doucet [13] reported that greater caloric restriction led to greater decline in energy expenditure. Furthermore, the decline in energy expenditure was associated with loss of FFM. These findings suggest the protection of FFM in the present study is linked to the modest caloric restriction and/ or the limited reduction in REE during weight loss.

While the study provides insight into changes in body composition and REE during weight loss, there are a number of limitations in the methodology. First, only individuals who had previously enrolled in the commercial weight loss program were included in the study, raising the potential for selection bias. A second constraint was related to lack of documentation for caloric intake and physical activity. Although clients reported and discussed caloric intake and physical activity with staff throughout the program, the information was not available for analysis. As a result, the current study could not assess the impact of these factors on body composition and REE. Finally, the study did not provide estimates of long-term weight loss success. Unless clients chose to extend enrollment, they had no contact with staff after completion of the 25week program. For these reasons, results of this study should be viewed as exploratory in nature.

\subsection{Conclusion}

Findings from this retrospective study indicate that significant decline in TBM is possible without loss of FFM and that metabolic adaptation may occur during weight reduction. Metabolic adaptation is a common occurrence during weight reduction, potentially slowing TBM and FM loss. In the current study, the use of serial REE measurements to guide target calories may have contributed to the continued loss of TBM and FM during the 25 week program. Furthermore, while the factor(s) responsible for maintenance of FFM during weight reduction cannot be definitively identified, the research indicates that presservation of FFM is related, directly or indirectly, to moderate caloric restriction and limited reduction in REE. From a practical perspective, maintaining FFM may limit decreases in muscle strength and aerobic capacity that often accompany weight loss $[15,16]$. In light of the current findings, the multifaceted relationship of body composition and energy metabolism is a critical topic for future research.

\section{REFERENCES}

[1] K. M. Flegal, M. D. Carroll, C. L. Ogden and L. R. Curtin, "Prevalence and Trends in Obesity Among US Adults, 1999-2008," Journal of the American Medical Association, Vol. 303, No. 3, 2010, pp. 235-241. doi:10.1001/jama.2009.2014

[2] International Food Information Council Foundation, "2010 Food and Health Survey: Consumer Attitudes toward Food Safety, Nutrition and Health," Washington DC, 2010.

[3] M. J. Franz, J. J. VanWormer, A. L. Crain, J. L. Boucher, T. Histon, W. Caplan, J. D. Bowman and N. P. Pronk, "Weight-Loss Outcomes: A Systematic Review and Metaanalysis of Weight-Loss Clinical Trials with a Minimum 1-year Follow-Up," Journal of the American Dietetic Association, Vol. 107, No. 10, 2007, pp. 1755-1767. doi:10.1016/i.jada.2007.07.017

[4] C. M. Lopez-Fontana, A. Sanchez-Villegas, M. A. Martinez-Gonzalez and J. A. Martinez, "Daily Physical Activity and Macronutrient Distribution of Low-Calorie Diets Jointly Affect Body Fat Reduction in Obese Women," Applied Physiology, Nutrition, and Metabolism, Vol. 34, No. 4, 2009, pp. 595-602. doi:10.1139/H09-015

[5] P. Chomentowski, J. J. Dube, F. Amati, M. Stefa-novicRacic, S. Zhu, F. G. Toledo and B. H. Good-Paster, "Moderate Exercise Attenuates the Loss of Skeletal Muscle 
Mass that Occurs with Intentional Caloric RestrictionInduced Weight Loss in Older, Overweight to Obese Adults," Journals of Gerontology. Series A, Biological Sciences and Medical Sciences, Vol. 64, No. 5, 2009, pp. 575-580. doi: $10.1093 /$ gerona/glp007

[6] E. M. Weinheimer, L. P. Sands and W. W. Camp-bell, "A Systematic Review of the Separate and Combined Effects of Energy Restriction and Exercise on Fat-Free Mass in Middle-Aged and Older Adults: Implications for Sarcopenic Obesity," Nutrition Reviews, Vol. 68, No. 7, 2010, pp. 375-388. doi: 10.1111/j.1753-4887.2010.00298.x

[7] E. Doucet, S. St-Pierre, N. Almeras, J. P. Despres, C. Bouchard and A. Tremblay, "Evidence for the Existence of Adaptive Thermogenesis During Weight Loss," British Journal of Nutrition, Vol. 85, No. 6, 2001, pp. 715-723. doi:10.1079/BJN2001348

[8] K. Goele, A. Bosy-Westphal, B. Rumcker, M. La- gerpusch and M. J. Muller, "Influence of Changes in Body Composition and Adaptive Thermogenesis on the Difference Between Measured and Predicted Weight Loss in Obese Women," Obesity Facts, Vol. 2, No. 2, 2009, pp. 105-109. doi: 10.1159/000210369

[9] L. M. Redman, L. K. Heilbronn, C. K. Martin, L. de Jonge, D. A. Williamson, J. P. Delany, E. Ravussin and C. T. Pennington, "Metabolic and Behavioral Compensations in Response to Caloric Restriction: Implications for the Maintenance of Weight Loss," Plos One, Vol. 4, No. 2, 2009, p. e4377. doi: 10.1371/journal.pone.0004377

[10] J. B. Weir, "New Methods for Calculating Meta-Bolic Rate with Special Reference to Protein Metabolism," Journal of Physiology, Vol. 109, No. 1-2, 1949, pp. 1-9.

[11] C. Kerksick, A. Thomas, B. Campbell, L. Taylor, C. Wilborn, B. Marcello, M. Roberts, E. Pfau, M. Grimstvedt, J.
Opusunju, T. Magrans-Courtney, C. Rasmussen, R. Wilson and R. B. Kreider, "Effects of a Popular Exercise and Weight Loss Program on Weight Loss, Body Composition, Energy Expenditure and Health in Obese Women," Nutrition and Metabolism, Vol. 6, 2009, p. 23. doi: 10.1186/1743-7075-6-23

[12] L. M. Redman, L. K. Heilbronn, C. K. Martin, A. Alfonso, S. R. Smith, E. Ravussin and C. T. Pennington, "Effect of Calorie Restriction with or without Exercise on Body Composition and Fat Distribution," Journal of Clinical Endocrinology and Metabolism, Vol. 92, No. 3, 2007, pp. 865-872. doi: $10.1210 /$ jc.2006-2184

[13] A. Schwartz and A. Doucet, "Relative Changes in Resting Energy Expenditure during Weight Loss: A Systematic Review," Obesity Reviews, Vol. 11, No. 7, 2010, pp. 531547. doi: 10.1111/j.1467-789X.2009.00654.x

[14] A. Tremblay and J. P. Chaput, "Adaptive Reduction in Thermogenesis and Resistance to Lose Fat in Obese Men," British Journal of Nutrition, Vol. 102, No. 4, 2009, pp. 488-492. doi: 10.1017/S0007114508207245

[15] G. R. Hunter, N. M. Byrne, B. Sirikul, J. R. Fer-nandez, P. A. Zuckerman, B. E. Darnell and B. A. Gower, "Resistance Training Conserves Fat-Free Mass and Resting Energy Expenditure Following Weight Loss," Obesity (Silver Spring), Vol. 16, No. 5, 2008, pp. 1045-1051. doi:10.1038/oby.2008.38

[16] E. P. Weiss, S. B. Racette, D. T. Villareal, L. Fon-tana, K. Steger-May, K. B. Schechtman, S. Klein, A. A. Ehsani and J. O. Holloszy, "Lower Extremity Muscle Size and Strength and Aerobic Capacity Decrease with Caloric Restriction but Not with Exercise-Induced Weight Loss," Journal of Applied Physiology, Vol. 102, No. 2, 2007, pp. 634-640. doi: 10.1152/japplphysiol.00853.2006 